\title{
On the heredity of retinitis pigmentosa
}

\author{
MARCELLE JAY \\ From Moorfields Eye Hospital, City Road, London EC1V 2PD
}

SUMmARY The aims of this study are: (1) to determine the frequencies of the various genetic forms of retinitis pigmentosa; and (2) to perform segregation analysis on autosomal dominant, autosomal recessive, and $\mathrm{X}$-linked families. The families studied consisted of 2 series of patients at Moorfields Eye Hospital: (1) 426 families seen in the Genetic Clinic; and (2) 289 families seen in the Electrodiagnostic Department. Comparison between the 2 series identified biases of ascertainment, and it was estimated that the combined series included $53 \%$ of simplex cases and a minimum of $15 \%$ of X-linked families. Segregation analysis of the Genetic Clinic series showed good agreement with expectation in autosomal dominant and X-linked families, but indicated that no more than $70 \%$ of all simplex cases were autosomal recessive. The rest of the simplex cases were mildly affected and may represent fresh autosomal dominant mutations, autosomal dominant transmission with reduced penetrance, the heterozygous state of X-linked disease in some of the females, and phenocopies.

\begin{abstract}
Many years ago a well dressed man who looked in excellent health, came to my desk in the out-patient room, at Moorfields, and in a somewhat excited manner declared 'I am going blind Sir! you can do nothing for me I know! It is in the family, and has been for centuries, and at the present time I know more than thirty who are either blind or on the way to it. When once it begins it always goes on; still I should be glad if you would look at my eyes.' I did so and found, as I expected, that he was the subject of retinitis pigmentosa.
\end{abstract}

The early authors classified the different genetic forms of retinitis pigmentosa using much the same system as did Nettleship ${ }^{2}$ in defining heredity in his series. Three main categories were recognised: (1) continuous, with direct inheritance in an unbroken line; (2) discontinuous, with parents normal but affected aunts, uncles, cousins, or grandparents; (3) collateral, where the parents were normal but sibs were affected. A fourth group consisted of cases inherited from both parents, when the heredity was termed double or reinforced.

In modern terminology the first group corresponds to autosomal dominant transmission; the second might be autosomal recessive, $\mathrm{X}$-linked, or autosomal dominant with reduced penetrance depending on the pedigree; and the third group probable autosomal recessive. It is very difficult, however, to analyse

Correspondence to Dr Marcelle Jay.

Part of a thesis accepted by the University of London for the degree of PhD. either the Nettleship ${ }^{2}$ or Bell ${ }^{3}$ series of pedigrees, as insufficient information is available.

Since 1925 the genetics of retinitis pigmentosa have been studied extensively in Europe,${ }^{4-10}$ and as a result the autosomal recessive mode of transmission has been considered to be the most common. ${ }^{11-20}$ The significance of $\mathrm{X}$-linked transmission in retinitis pigmentosa was probably recognised intuitively by Nettleship (1845-1913), and there are numerous examples of this mode of transmission in the early literature. ${ }^{21-30}$ The most significant findings, particularly in the recognition of the carrier state in the female heterozygote, were by Falls and Cotterman ${ }^{23}$ and by Bird. ${ }^{31}$

There have been several studies since 1961 comparing the proportions of the different genetic forms of retinitis pigmentosa in various parts of the world: Switzerland ${ }^{45}$ Belgium, ${ }^{832}$ Israel, ${ }^{33}$ Japan, ${ }^{30} 34{ }^{35}$ the USSR, ${ }^{36}$ the United Kingdom, ${ }^{93738}$ and the USA.$^{39-41}$ Some of these studies were based on clinical and hospital records, and others were obtained from various samples of well-defined populations. The proportions of the different genetic forms vary from one series to another, and they reflect the ethnic and other socioeconomic factors which influence the prevalence of any genetically determined disease in a given population (Table 1).

Consanguinity rates vary: in Switzerland and in Israel they are relatively high, whereas in $\mathrm{Japan}^{30}$ they 
Table 1 Frequency of different genetic forms

\begin{tabular}{|c|c|c|c|c|c|}
\hline Author & $A D$ & $A R$ & $X L$ & $S p$ & $\begin{array}{l}\text { No. of } \\
\text { cases }\end{array}$ \\
\hline Ammann et al. ${ }^{4}$ & $9 \%$ & $90 \%$ & $1 \%$ & & 153 \\
\hline Boughman $^{39}$ & $10 \%$ & $81 \cdot 1 \%$ & $8.9 \%$ & & 608 \\
\hline Fishman $^{40 *}$ & $26 \%$ & $19 \%$ & $16 \%$ & $38 \%$ & 173 \\
\hline François $^{8}$ & $19 \cdot 5 \%$ & $37 \%$ & $4 \cdot 5 \%$ & $39 \%$ & $?$ \\
\hline François and Verriest ${ }^{44}$ & $19 \%$ & $35 \%$ & $4 \cdot 1 \%$ & $41 \cdot 3 \%$ & 153 \\
\hline Imaizumi $^{47}$ & $2 \cdot 1 \%$ & $40 \cdot 1 \%$ & & $43 \cdot 2 \%$ & 1091 \\
\hline Jay9 & $39 \%$ & $15 \%$ & $25 \%$ & $21 \%$ & 77 \\
\hline $\mathrm{Jay}^{37}$ & $38 \cdot 7 \%$ & $17 \%$ & $23 \cdot 6 \%$ & $20 \cdot 7 \%$ & 106 \\
\hline $\mathrm{Jay}^{38}$ & $39 \%$ & $15 \%$ & $25 \%$ & $21 \%$ & 300 \\
\hline Motohashi ${ }^{35}$ & & & & $83 \%$ & 519 \\
\hline Panteleeva $^{36}$ & $12 \cdot 7 \%$ & $27.9 \%$ & $1 \cdot 1 \%$ & $?$ & 678 \\
\hline Pearlman et al. ${ }^{41}$ & $5.9 \%$ & $13 \cdot 2 \%$ & $7 \cdot 4 \%$ & $73.5 \%$ & 68 \\
\hline Tanabe $^{30}$ : group $\mathbf{A}$ & & $54 \cdot 6 \%$ & & & 1650 \\
\hline group B & & $64 \cdot 7 \%$ & & & 839 \\
\hline
\end{tabular}

*The remaining $1 \%$ was of undetermined genetic type. $\mathrm{AD}=$ autosomal dominant. $\mathrm{AR}=$ autosomal recessive. $\mathrm{XL}=\mathrm{X}$-linked. $\mathrm{Sp}=\mathrm{sporadic}$.

are low and similar to those in the $\mathrm{UK}^{42}$ and in the USA. ${ }^{39}$ The sex ratio, from which calculations of an expected proportion of $\mathrm{X}$-linked cases can be made, is not always indicative of the true distribution of $\mathrm{X}$-linked disease. In the USSR, for example, there was a significant excess of female probands (415 females to 263 males). Such an excess of female probands is a bias of ascertainment which might surprise an ophthalmologist, but is a common experience of clinical geneticists.

The aims of the present study are to determine the frequencies of the different genetic forms of retinitis pigmentosa, to perform segregation analysis where possible, and to analyse certain factors which are relevant to genetic counsellors faced with a patient in whom the diagnosis of retinitis pigmentosa has been established.

\section{Patients and methods}

The patients in this study were drawn from 2 different sources and form separate groups.

(1) 426 families with retinitis pigmentosa were seen in the Genetic Clinic of Moorfields Eye Hospital in the period from July 1969 to August 1979 (and this series will be referred to as the GC series). Patients in these families were referred mainly from general clinics within the hospital, though a number were referred from other hospitals or from general practitioners. They do not, however, represent every case of retinitis pigmentosa seen within the hospital during this period. Their referral was usually for assessment, for genetic counselling, or stimulated by the various research projects being carried out in the Genetic Clinic, and patients in this series were seen by one of 3 clinicians.

(2) The Electrodiagnostic Department of
Moorfields Eye Hospital has been in existence since 1964 , and approximately 8500 patients were referred to the department up to August 1979. Their sources of referral are from general clinics within the hospital and from consultants at other hospitals. A search through these records yielded 289 families not previously known to the Genetic Clinic, which form a group called the ED series. A high proportion of these patients were referred to the department for diagnostic purposes.

The GC series and the ED series probably represent the majority of patients with retinitis pigmentosa who have been seen at Moorfields Eye Hospital, though this combined series does not represent complete ascertainment.

METHOD OF RECORDING THE DATA

Every family was recorded on special Genetic Clinic notes, which included a full family history, a record of the pedigree, and clinical information. The data recorded include name, address, date of birth, hospital and series numbers, nationality, race, religion, pedigree (with space for dates of birth of relatives), and consanguinity. The occupation was sometimes recorded. Individual members of families were entered into a computerised index with the following attributes concerning each entry: Surname, maiden name, initials, series number, sex, year of birth, mode of transmission, clinical status, area of origin.

\section{CRITERIA FOR MODE OF TRANSMISSION}

The mode of transmission was divided into a number of categories which could be either grouped together or considered separately for various analyses. The criteria for autosomal dominant transmission were: similar clinical manifestations in males and females; 2 
or more generations of direct transmission; and preferably, but not necessarily, father-to-son transmission.

For the purpose of this study the criteria for autosomal recessive transmission were either evidence of parental consanguinity, or the affected individual had parents who were believed to be homozygous or heterozygous for autosomal recessive retinitis pigmentosa on the basis of the family history. Families satisfying these criteria were labelled 'probably autosomal recessive.'

Other families were recognised as being possibly autosomal recessive, and these were either multiplex ( 2 or more affected sibs) or simplex (one affected member in a sibship). The multiplex were divided into 2 groups: (a) male only affected, which could be autosomal recessive or X-linked and termed 'male multiplex'; and $(b)$ male and female affected or only females affected, termed 'mixed multiplex.' All the simplex cases (without parental consanguinity) were also recognised as being possibly autosomal recessive but were further subdivided according to clinical criteria of age and severity of the disease ${ }^{43}$ into the following categories: clinically autosomal dominant (mildly affected); clinically autosomal recessive (severely affected females); clinically autosomal recessive or X-linked (severely affected males); uncategorised (intermediate in severity).

$\mathrm{X}$-linked transmission in the GC series was evident from the pedigree and from the examination of heterozygotes, but evidence of an affected male maternal relative and an apparently unaffected mother was taken to be sufficient to assume $\mathrm{X}$-linked inheritance in the ED series. A further category labelled 'transmission unknown' was assigned to those few families where, although there was more than one affected member, the mode of transmission could not be deduced from the pedigree.

The attribute of clinical status was divided into: affected, obligate heterozygote, possible hetero- zygote unaffected, unknown, and possibly affected. The category 'unaffected' has been kept exclusively for parents of simplex cases and of all multiplex cases, other than those considered to be probably autosomal recessive. The category 'unknown' usually refers to the members of early generations in the autosomal dominant or X-linked families, and the 'possibly affected' is an at-risk category used for children of affected subjects with autosomal dominant or Xlinked inheritance.

The code for area of origin was based on a variant of the system used by the regional health authorities for the various counties.

The index has been used primarily for identifying families and comparing surnames in pedigrees. There is in addition another file of the common and duplicated surnames occurring in the main index. The data in the computer are revised at regular intervals and updated whenever additional information becomes available.

\section{Results and discussion}

\section{GENETIC CLINIC SERIES}

Distribution of probands. The Genetic Clinic series consists of $\mathbf{4 2 6}$ families in which a firm diagnosis of retinitis pigmentosa has been made. The distribution of families, probands, and total number of affected subjects according to genetic form is shown in Table 2 . The proportion of $\mathrm{X}$-linked families, which has always been higher than in any other series in the literature, is identified clinically as $15.7 \%$, and this group has a large number of obligate heterozygotes among the probands.

The number of apparently unaffected probands was $9.6 \%$ of the total and reflects the concern of asymptomatic subjects who have affected relatives for the implications to their own children. This is particularly relevant for women and is illustrated in the $\mathrm{X}$-linked families, in which between one-quarter

Table 2 Number and sex distribution of families, probands, and affected subjects according to genetic form in GC series

\begin{tabular}{|c|c|c|c|c|c|c|c|c|}
\hline \multirow[t]{2}{*}{ Transmission } & \multicolumn{2}{|l|}{ Families } & \multicolumn{4}{|c|}{ Probands } & \multicolumn{2}{|c|}{$\begin{array}{l}\text { Total No } \\
\text { affected }\end{array}$} \\
\hline & Number & $\%$ & $M$ & $F$ & $m$ & $f$ & $M$ & $F$ \\
\hline AD & 104 & $24 \cdot 4$ & 30 & 63 & 3 & 8 & 211 & 228 \\
\hline Probably AR & 29 & $6 \cdot 8$ & 17 & 11 & 1 & 1 & 25 & 22 \\
\hline X-linked & 67 & $15 \cdot 7$ & 44 & - & 4 & $19^{*}$ & 189 & $187^{*}$ \\
\hline Mixed multiplex & 28 & $6 \cdot 6$ & 5 & 23 & 1 & 3 & 27 & 42 \\
\hline Male multiplex & 19 & $4 \cdot 5$ & 16 & - & 2 & 2 & 44 & - \\
\hline Simplex & 175 & $41 \cdot 1$ & 103 & 72 & & & 103 & 72 \\
\hline Adopted & 4 & 0.9 & 2 & 2 & & & 2 & 2 \\
\hline Totals & 426 & & 217 & $17 \overline{1}$ & 11 & 33 & 601 & 553 \\
\hline
\end{tabular}

*Eighteen of the 19 probands were identified as heterozygotes, and all the 'affected' females were heterozygotes.

$M=$ affected male. $F=$ affected female. $m=$ unaffected male. $f=$ unaffected female. 
Table 3 Sex distribution of simplex cases in the GC series according to clinical severity

\begin{tabular}{lccc}
\hline & Males & Females & Totals \\
\hline Clinically AR (severely affected & 31 & 15 & 46 \\
Clinically AD (mildly affected) & 27 & 23 & 50 \\
Unclassified & & & \\
(intermediate in severity) & 45 & 34 & 79 \\
Totals & 103 & 72 & 175 \\
\hline
\end{tabular}

and one-third of these families were ascertained through the females, and where 18 out of 19 women were discovered to be heterozygotes. The large number of female probands in the X-linked families is undoubtedly related to the demand for genetic counselling in severe disease. It is also possibly a consequence of the well-publicised research interest of the clinicians at Moorfields Eye Hospital.

The proportion of simplex cases is $41.1 \%$, and their division according to clinical form is shown in Table 3 . There are 9 male and 8 female simplex cases among the probands in the autosomal recessive group, and if all simplex cases with or without parental consanguinity are considered as a group there are 112 male and 80 female simplex cases. The excess of males in this group is statistically significant $\left(\chi^{2}=5 \cdot 33\right.$, $\mathrm{p}<0 \cdot 02)$. Similarly, if all simplex and multiplex cases, with or without consanguinity are grouped together, there is a total of 172 affected males and 113 affected females. The deviation from the expected sex distribution is highly significant $\left(\chi^{2}=12 \cdot 21, \mathrm{p}<0 \cdot 01\right)$.

There is a significant excess of females among the probands in the autosomal dominant families (63 females to 30 males), but the excess of females among all affected members of the same group is no longer significant (228 females to 211 males), indicating a bias of ascertainment in this group. This may be due to various factors such as the economic implications of occupation which may weigh more heavily on men than on women. Women may be more prone than men to seek specialist advice on prognosis and possible treatment, and they appear more likely to seek genetic counselling.

Comparison of frequency of genetic forms. The frequency of the various genetic forms differs when calculated as a proportion of the families on the one hand, and as a proportion of the total number of affected individuals in the pedigree on the other. The proportion of autosomal dominant disease is much higher (38\%) among affected individuals than among families, where it is $24.4 \%$. Similarly, the X-linked proportion is $15.7 \%$ among families and $32.6 \%$ among affected individuals. This clearly illustrates the bias which is introduced when a series is based on affected individuals with a positive family history.
The frequency of autosomal dominant retinitis pigmentosa among families $(24.4 \%)$ is much lower than the $39 \%$ found in previous studies. ${ }^{93738}$ This may be the result of a different division of the series or of the relatively higher proportion of $\mathrm{X}$-linked and simplex cases in the present series. The proportion of autosomal dominant disease in the present study is comparable to 2 oher studies: François $^{8}$ found $19 \cdot 5 \%$, and Fishman ${ }^{40}$ found $26 \%$.

The frequency of autosomal recessive retinitis pigmentosa is $6.4 \%$, which does not take into account all the simplex and multiplex cases which may be recessive after removal of the $\mathrm{X}$-linked proportion, and this topic will be discussed in the light of the results of segregation analysis.

The estimation of the frequency of genetic forms among families shows that the proportion of simplex cases is slightly higher than in a previous study based on 305 families. ${ }^{43}$ This may be due to more generalised referral from various sources or from a greater demand by patients for assessment and counselling.

Estimation of $X$-linked form in simplex and multiplex sibships. A method suggested by Fraser ${ }^{45}$ was used to estimate the $\mathrm{X}$-linked proportion in these groups, based on the comparison of sibships with affected members of one sex only. With autosomal recessive inheritance there should be as many sibships of males only affected as of females only affected. The defined autosomal recessive sibships are removed from the analysis, and the excess of sibships with only males affected can be directly attributable to $X$-linked inheritance. Furthermore a sibship with, for example, 3 affected children may be distributed in 4 different combinations: 3 males, 3 females, 2 males and 1 female, or 1 male and 2 females. If $n_{k}$ is the number of sibships other than male only affected with $\mathrm{k}$ affected members, then the number of sibships with only male affected is:

$$
\frac{n_{k}}{2^{k}-1}
$$

This calculated number of sibships is compared with the observed number of sibships with only males affected, and the excess corresponds to the number of sibships which may be attributable to X-linked transmission. This excess may also be converted to a simplex number of $\mathrm{X}$-linked cases by multiplying it by the simplex:multiplex ratio obtained from the autosomal recessive group. These methods will give an approximation of the proportion of $\mathrm{X}$-linked cases, and they have been applied to all multiplex families in the GC series (Table 4). The results showed that 11.76 out of the 19 male multiplex sibships in this series could be attributable to 
Table 4 Expected/observed proportion of male multiplex sibships in GC series

\begin{tabular}{|c|c|c|c|c|c|}
\hline \multirow{2}{*}{$\begin{array}{l}\text { No. of } \\
\text { affected }\end{array}$} & \multirow{2}{*}{$\begin{array}{l}\text { No. of } \\
\text { mixed } \\
\text { multiplex }\end{array}$} & \multicolumn{4}{|c|}{ Male only affected } \\
\hline & & \multicolumn{2}{|c|}{ Expected } & Observed & Excess \\
\hline 2 & 18 & $6 \cdot 00^{\circ}$ & & 14 & $8 \cdot 00$ \\
\hline 3 & 8 & $1 \cdot 14$ & & 4 & $2 \cdot 86$ \\
\hline 4 & 1 & 0.07 & & 1 & 0.93 \\
\hline 5 & 1 & 0.03 & & 0 & -0.03 \\
\hline Totals & 28 & $7 \cdot 24$ & & 19 & $11 \cdot 76$ \\
\hline \multicolumn{2}{|c|}{ Affected of one sex only } & & \multicolumn{3}{|c|}{ Affected of both sexes } \\
\hline Male & Female & & Male & Female & \\
\hline 44 & 14 & & 27 & 28 & \\
\hline
\end{tabular}

$\mathrm{X}$-linked transmission. Of the 19 male multiplex sibships there were 12 where the mother was unavailable for examination, and in $\mathbf{8}$ of these there were no daughters. The daughters in the remaining 4 sibships were under the age of 10 years and no abnormality could be detected in them.

The simplex:multiplex ratio among the 'probably autosomal recessive' group is $17: 12$, and, if it is assumed that the same ratio may be applied to the excess of male multiplex sibships, the estimated number of simplex cases with $\mathrm{X}$-linked transmission is between 16 and $17(16 \cdot 66)$. If a minimum of 16 males are deducted from the 76 males (simplex cases other than mildly affected), the remaining 60 males may be compared with the 49 females of the same clinical status, and the excess of males is no longer statistically significant $\left(\chi^{2}=1 \cdot 11,0 \cdot 2<p<0 \cdot 3\right)$.

The proportion of $\mathrm{X}$-linked families, which has always been higher than in any other series in the literature, is identified clinically as $15.7 \%$ and has been calculated as $22 \cdot 3 \%(95 / 426)$. There appears to be a large proportion of sibships which were presumably not identified as being X-linked by examination of the heterozygote or the recognition of the phenotype of the isolated hemizygote. Although every effort is usually made to examine the possible obligate heterozygotes where $\mathrm{X}$-linked disease is suspected, there are inevitably some cases where the mother is not available, or where the existing daughters are too young for tests to be conclusive. This does not exclude the possibility of subsequent changes in the identified status of these girls, but illustrates the clinical problems in the detection of the heterozygous state and the difficulties in making the correct genetic diagnosis at the time of ascertainment. Similarly, the estimation of 16 out of 76 simplex males with severe or moderately severe disease as being $\mathrm{X}$-linked shows that the hemizygous phenotype is not identifiable clinically in the absence of a corroborative family history.

$\mathrm{X}$-linked retinitis pigmentosa was the subject of a detailed study at Moorfields Eye Hospital, ${ }^{31}$ and it is possible that a high proportion of $\mathrm{X}$-linked families in the country has now been ascertained, in contrast to autosomal dominant families, where the disease is milder and ascertainment less complete. The number of patients with identifiable X-linked retinitis pigmentosa is still rising, but many of these belong to families already ascertained. There are also one or 2 instances in which 2 or 3 small $\mathrm{X}$-linked pedigrees have been found to be parts of one large pedigree, and presumably this occurrence will become more common with time.

The relatively high proportion of $\mathrm{X}$-linked retinitis pigmentosa in this series may be due to the higher prevalence of this form of the disease in this country than in others. A study in the USA in a series of comparable $\operatorname{size}^{39}$ identifies the proportion of $\mathrm{X}$-linked as $8.9 \%$, the data being derived from a questionnaire. However, in view of all the clinical problems of the identification of this form, the proportion of $\mathrm{X}$-linked retinitis pigmentosa in the USA may well be considerably higher than $8.9 \%$. Unfortunately, the extensive study in $\mathrm{Japan}^{30}$ gave no indication of the proportion of the X-linked form.

Another reason for the high proportion of X-linked retinitis pigmentosa in this study is the high referral rate, which results from several factors. These include: the occurrence of severe disease in several generations (and in some families with many affected members); the known interest of clinicians at Moorfields Eye Hospital in X-linked disorders; and the observation that a number of obligate heterozygotes have deduced the mode of inheritance of the disorder in their families, and have requested genetic counselling and advice on the prognosis of the disease not only for themselves but often for their children. It is also evident that the clinical identification of heterozygotes may be difficult, particularly when they are young and the fundus changes may be minimal.

\section{ELECTRODIAGNOSTIC SERIES}

Distribution of probands. The electrodiagnostic series consists of 289 families in which a tentative diagnosis of retinitis pigmentosa was made by a clinician from a general clinic at Moorfields Eye Hospital or from another hospital and patients were referred to establish a diagnosis. The distribution of families and probands according to genetic form and sex is shown in Table 5. The sex distribution among probands in all simplex and multiplex cases with or without consanguinity is 142 males and 90 females. The deviation from the expected sex ratio is highly significant $\left(\chi^{2}=11 \cdot 66, p<0 \cdot 01\right)$, and consistent with a 
Table 5 Number and distribution of probands according to genetic forms in the ED series

\begin{tabular}{lrrrr}
\hline Transmission & $\begin{array}{c}\text { No. of } \\
\text { families }\end{array}$ & $\%$ & \multicolumn{2}{c}{ Probands } \\
\cline { 3 - 5 } & & & Males & Females \\
\hline AD & 43 & $14 \cdot 9$ & 19 & 24 \\
Probably AR & 4 & $1 \cdot 4$ & 2 & 2 \\
X-linked & 11 & $3 \cdot 8$ & 9 & 2 \\
Mixed multiplex & 13 & $4 \cdot 5$ & 7 & 6 \\
Male multiplex & 12 & $4 \cdot 2$ & 12 & -2 \\
Simplex & 203 & $70 \cdot 2$ & 121 & 82 \\
Adopted & 3 & $0 \cdot 9$ & 1 & 2 \\
Total & 289 & & 171 & 118 \\
\hline
\end{tabular}

proportion of clinically unidentifiable $\mathrm{X}$-linked cases similar to that calculated in the GC series.

Frequency of genetic forms. This series differs from the Genetic Clinic series in the manner in which it was ascertained. The cases in this series were referred solely for diagnosis; they do not include those patients previously ascertained in the Genetic Clinic, and there is therefore a bias in favour of cases without a family history. This bias is reflected in the high proportion of simplex cases $(70.2 \%)$ and the low proportion of autosomal dominant $(14.9 \%)$ and of $\mathrm{X}$-linked families $(3 \cdot 8 \%)$. The whole structure of the Electrodiagnostic Series is predominantly clinically orientated and in the context of this study can only indicate the possible sources of bias in the Genetic Clinic series.

COMBINED MOORFIELDS EYE HOSPITAL SERIES Despite the fact that reliable family details are incomplete in the ED series it is interesting to consider the GC and the ED series together. The bias towards cases with a positive family history in the GC series is compensated by the bias towards simplex cases in the ED series, and the combined Moorfields Eye Hospital (MEH) series is more representative of the hospital population, even although it does not include every patient with retinitis pigmentosa seen at Moorfields Eye Hospital.

The MEH series contains 715 families with retinitis pigmentosa, and there are 378 simplex cases without parental consanguinity, a proportion of $52.9 \%$. Few other series in the literature have a comparable number of families except Boughman, ${ }^{39}$ where the data showed that $161(44 \cdot 1 \%)$ were simplex families and the remainder were multiplex. Nettleship ${ }^{46}$ found $50 \%$ of simplex cases in his series of 1381 cases, and Imaizumi $^{47}$ found $43.2 \%$ of sporadic cases in a series of 1091 cases. The proportion of simplex cases in the MEH series among the total number of affected individuals, as distinct from families, is lower than $52.9 \%$.
The proportion of autosomal dominant families in the MEH series is $20.6 \%$, which is comparable to the $19 \cdot 5 \%$ found by François ${ }^{8}$ but approximately half the proportion found in previous studies on patients attending the Genetic Clinic. ${ }^{97-38}$ The relative frequencies of $\mathrm{X}$-linked and autosomal recessive families depend on calculations which cannot be applied to the ED series, although it can be seen that there is a minimum of $15 \%(106 / 715) \mathrm{X}$-linked families in the combined series. This proportion is probably very similar to the $16 \%$ found by Fishman ${ }^{40}$ in a much smaller series of 173 cases, but is lower than the consistent value of $25 \%$ found in previous studies on patients from the Genetic Clinic. ${ }^{937} 38$

It is tempting to speculate to what degree the proportion of $52.9 \%$ of simplex cases and a minimum of $15 \%$ of $\mathrm{X}$-linked families in the MEH series is representative of the population in the country as a whole. Moorfields Eye Hospital has a special status. It is not solely a secondary referral hospital, for its has both a large general outpatient department and a large casualty department with an 'open door' policy, and 249312 outpatients were seen in the 2 branches of the hospital in 1978. ${ }^{48}$ A large proportion of the outpatients are referred from general practitioners, and a significant proportion live outside London.

Although there is provision for race and religion on the special Genetic Clinic notes, these are not invariably recorded. It is apparent from the limited data available, and from the number of consanguineous marriages among Muslims and Hindus, that the immigrant population in south-east England is represented in the GC series, although their exact proportion is not known. The Electrodiagnostic Clinic is even more cosmopolitan in the ethnic origin of its patients. Similarly, the patient's occupation or profession is not always recorded. It seems, however, from. the data which are available that retinitis pigmentosa is no respecter of social class and that it is not more prevalent among the so-called deprived sector of the community.

All the evidence indicates that the proportion of $52.9 \%$ of simplex cases without parental consanguinity, and a minimum of $15 \%$ of $X$-linked families, may be representative of the population of south-east England. The frequency of $\mathrm{X}$-linked disease is related to families and not cases, and the families are drawn from the whole of England and Wales, with no evidence so far of any clustering in a particular region. It must be concluded that $\mathrm{X}$-linked retinitis pigmentosa is a relatively common form of the disease throughout this country.

\author{
SEGREGATION ANALYSIS OF GENETIC CLINIC \\ SERIES
}

Segregation analysis was performed only on the 
Genetic Clinic series, where the family structure was known in all but a few cases.

Possible autosomal recessive families. All known autosomal dominant, $\mathrm{X}$-linked, and adopted families were removed from the group for analysis, and the remainder consisted of: the probably autosomal recessive group; all the multiplex cases; and all the simplex cases. (Male-only multiplex sibships were included, since even those which may be X-linked do not affect the segregation ratio.)

Various methods of segregation analysis are available. ${ }^{49-51} \mathrm{~A}$ number of these depend on complete ascertainment and cannot therefore be applied to this series. The method of choice is that described by $\mathrm{Crow}^{52}$ and is an adaptation of earlier methods. ${ }^{534}$ This method is similar to the Weinberg 'proband' method but adapted for use in multiple incomplete ascertainment. A first approximation of the segregation ratio $p_{0}$ is estimated by obtaining the ratio of affected sibs to the total number of sibs of probands for the pooled families.

$$
\begin{aligned}
& \begin{array}{l}
\text { If } a=\text { number of probands } \\
s=\text { sibship size } \\
r=\text { number of affected }
\end{array} \\
& \text { then } \\
& \qquad p_{0}=\frac{\Sigma a(r-1)}{\Sigma a(s-1)}
\end{aligned}
$$

A parameter $(\pi)$, known as the probability of ascertainment is calculated from the equation

$$
\pi=\frac{\Sigma \mathrm{a}(\mathrm{a}-1)}{\Sigma \mathrm{a}(\mathrm{r}-1)}
$$

The corrections suggested by $\mathrm{Crow}^{52}$ consist of a correction factor $\mathrm{C}$ defined by

$$
1 / \mathrm{C}=1+\pi+p_{0} \pi(s-3)
$$

which is applied to calculate a more accurate value of the segregation ratio $p$ where

$$
\mathrm{p}=\frac{\Sigma \mathrm{Ca}(\mathrm{r}-1)}{\Sigma \mathrm{Ca}(\mathrm{s}-1)}
$$

The effect of $C$ is to reduce the contribution from the larger sized families, so that $p$ is greater than $p_{0}$. The variance $V_{p}$ is given by

$$
V_{p}=\frac{p(1-p)}{\Sigma C a(s-1)}
$$

Crow $^{52}$ also suggested calculating the 2 limiting values of $p$, corresponding to truncate selection where $\pi=1$, and single selection where $\pi=0$. The value of $p$ for truncate selection is the upper limiting value, and the value of $p$ for single selection is the lower limiting value of the segregation ratio.
The clinical division of simplex cases into groups which were clinically autosomal dominant (with mild disease) or autosomal recessive (with severe disease) provided a basis for a similar division for the purpose of segregation analysis. The methods outlined above were therefore used on 3 groups depending on the selection of simplex cases included. Group 1 consisted of all multiplex sibships, all probably autosomal recessive families, and all simplex cases whatever the clinical category. Group 2 was similar to group 1 except that the simplex cases which were clinically autosomal dominant were excluded. And group 3 was also similar to group 1 except that only those simplex cases which were clinically autosomal recessive were included. The results of segregation analysis on the 3 groups of possibly autosomal recessive families are summarised in Table 6 . The value of the segregation ratio varied according to the methods used, with single selection giving low values, truncate selection giving high values, and multiple selection giving intermediate values. Similarly, group 2 which included simplex cases which were clinically autosomal recessive or unclassified consistently gave intermediate values of the segregation ratio. Low values were obtained for group 1 and high values for group 3.

Since the distribution of simplex cases in the GC series was a deciding factor in the estimation of the segregation ratio, the equation derived by Morton ${ }^{55}$ and Morton and Chung ${ }^{56}$ in studies of muscular dystrophy was used to estimate the proportion of sporadic cases or phenocopies. According to Morton, if $x$ is the proportion of sporadics among the simplex cases, and $\mathrm{s}, \mathrm{p}$, and $\pi$ are as previously defined, then the distribution $P$ of families with one affected member is given by:

\begin{tabular}{|c|c|c|c|}
\hline Method & Group 1 & Group 2 & Group 3 \\
\hline Multiple selection & $\begin{array}{l}\mathrm{p}=0.135 \\
\sigma=0.014\end{array}$ & $\begin{array}{l}\mathrm{p}=0 \cdot 170 \\
\sigma=0 \cdot 018\end{array}$ & $\begin{array}{l}\mathrm{p}=0.263 \\
\sigma=0.025\end{array}$ \\
\hline Single selection & $\begin{array}{l}\mathrm{p}=0 \cdot 122 \\
\sigma=0.013\end{array}$ & $\begin{array}{l}\mathrm{p}=0.155 \\
\sigma=0.016\end{array}$ & $\begin{array}{l}\mathrm{p}=0.243 \\
\sigma=0.023\end{array}$ \\
\hline $\begin{array}{l}\text { Truncate selection } \\
\text { Proportion of smoradics }\end{array}$ & $\begin{array}{l}\mathrm{p}=0.243 \\
\sigma=0.021 \\
\mathrm{x}=0.285\end{array}$ & $\begin{array}{l}\mathrm{p}=0.283 \\
\sigma=0.024\end{array}$ & $\begin{array}{l}\mathrm{p}=0.383 \\
\sigma=0.039\end{array}$ \\
\hline Proportion of sporadics & $x=0 \cdot 285$ & $x=0 \cdot 104$ & $x=-0.371$ \\
\hline
\end{tabular}

$$
P=\frac{\operatorname{sp} \pi\left[\mathrm{x}+(1-\mathrm{x}) \mathrm{q}^{\mathrm{s}-1}\right]}{\mathrm{xsp} \pi+(1-\mathrm{x})\left[1-(1-\mathrm{p} \pi)^{\mathrm{s}}\right]}
$$

$P$ is calculated by using 2 trial values of $x$ for every value of $\mathbf{s}$, and the expected number of sibships with one affected member is obtained from the calculated values of $P$. The value of $x$ is then obtained by linear interpolation.

Table 6 Summary of results of segregation analysis of autosomal recessive families in GC series 
The value of $p$ used in this equation was arbitrarily chosen to be the estimated value obtained from multiple selection applied to group 2, which was considered to be the closest to the true figure. The calculation of $\mathbf{x}$, the proportion of sporadics, was made for all 3 groups for purposes of comparison and for some indication of the validity of the assumptions made in their definition. The results show that for group 1 which included all simplex cases, $x=0 \cdot 29$; for group 2 , which excluded mildly affected simplex cases, $x=0 \cdot 10$; and for group 3 , which included only severely affected simplex cases termed 'clinically autosomal recessive,' $\mathrm{x}=-\mathbf{0} \cdot 37$.

Segregation analysis was performed initially on all simplex and multiplex cases, with or without consanguinity, which could be autosomal recessive. The value of the segregation ratio obtained by multiple selection is low with $p=0 \cdot 135$, a finding common to other series. ${ }^{53}$ While the segregation ratio is expressed as a proportion, it is derived from the summation of affected sibs and the summation of all sibs of probands. A low segregation ratio may therefore be the result of a deficit of multiplex cases and/or an excess of simplex cases.

The deficit of multiplex cases may be due to late age of onset causing belated ascertainment of affected sibs, although this is unlikely, as the mean age of onset in this study was found to be 12.7 years and may well be lower. The mean family size in simplex cases did not differ significantly from that in multiplex cases, and it was therefore considered that the low value of the segregation ratio was due to the large number of simplex cases included in the analysis.

The simplex cases formed a clinically heterogeneous group, and this study has already demonstrated that the phenotype of the hemizygote in X-linked disease is not distinguishable from that of the male with autosomal recessive disease. Similarly, the phenotype of the obligate heterozygote in X-linked disease may not always be distinguished from that of the female with autosomal dominant disease. In the absence of any method demonstrating a measurable enzyme defect in autosomal recessive disease it was assumed that the autosomal recessive phenotype is generally one expressing severe disease. Thus for the purpose of simple segregation analysis the division of simplex cases according to clinical type, as shown on Table 3, was used as a criterion for autosomal recessive transmission.

The values of $p$ obtained for single selection in each group correspond to the case where there is only one proband per family, and those obtained for truncate selection correspond to the extreme case where every affected member is a proband. There were several families with more than 2 affected members, and it would have been most unlikely that they were all independently ascertained. Truncate selection is therefore a limiting case, and it is a useful tool in population genetics, but it does not correspond to the reality of practice at Moorfields Eye Hospital. The most acceptable value of the segregation ratio was that obtained by calculations from multiple selection, and it can be seen from Table 6 that in group 2 the value of $p$ was $0 \cdot 17$ with a standard deviation of 0.018 . The value of $p$ therefore lies between $0 \cdot 15$ and 0.20 within $95 \%$ confidence limits.

The assumption that all simplex cases in this series are not all autosomal recessive was further tested by using a statistical probability function. This function was derived from a study of muscular dystrophy ${ }^{56}$ and is 'used to calculate the proportion of 'sporadic' or nongenetic among simplex cases. It was applied to the data of the GC series based on a segregation ratio of $p=0 \cdot 17$, and the results confirmed a few assumptions previously made. In group 1 , which included all 175 simplex cases, the proportion of sporadic cases was $28.5 \%(50 / 175)$. When this number was adjusted for the calculated number of $16 \mathrm{X}$-linked cases, the number of sporadic cases in group 1 was 34 , or a proportion of $19.4 \%$. In group 3 there were manifestly too few simplex cases included, which led to a negative value for the proportion of sporadic cases. The most interesting result was in group 2, where the proportion of sporadic among the 125 simplex cases was $10.4 \%$ (13 cases). This result implies that after removal of the X-linked cases there were no sporadic cases or phenocopies in group 2 .

The genetic status of the group of 50 simplex cases termed 'clinically autosomal dominant' is a matter for discussion. A number of females within this group may be X-linked heterozygotes, because the carrier state in X-linked disease is not always identifiable by the methods at present in use in the absence of a typical pedigree. A certain number of males and females within this group may represent fresh autosomal dominant mutations. The data on parental age in this group are incomplete and the ages are not corrected for parity, but there are, however, 9 instances where the age difference between spouses is equal to or greater than 7 years. These results indicate that there may be some fresh autosomal dominant mutations in this group. Nevertheless the results of mathematical analysis alone imply that there may be as many as $34(19.4 \%)$ sporadic cases or phenocopies among the total number of simplex cases.

By definition this group of 'clinically autosomal dominant' cases has a relatively late onset of mild disease, and the parents are frequently not available for examination. It is possible that a certain number of these parents may have been subclinically affected or even that the grandparents may have been mildly affected. Some of these cases may therefore represent 
a group of autosomal dominant retinitis pigmentosa with or without reduced penetrance, with a small number of fresh autosomal dominant mutations. It is also possible that a number of these mildly affected simplex cases are clinically unidentifiable phenocopies.

The statistical analysis has shown that out of 175 simplex cases it may be assumed that 109 are autosomal recessive and 16 are $\mathrm{X}$-linked males. The remaining $\mathbf{5 0}$ are mildly affected, and some of these may be fresh autosomal dominant mutations. The remainder may be $\mathrm{X}$-linked heterozygotes, autosomal dominant cases whose parents have escaped detection, or possibly clinically unidentifiable manifesting heterozygotes, or phenocopies. While it is possible that a few of these mildly affected simplex cases are autosomal recessive, the results of segregation analysis indicate that this group, if it exists, is small.

Autosomal dominant families. The method used was that given by Emery. ${ }^{49}$ The number of normal and affected offspring of all affected by normal matings is compared with the expected number and a $\chi^{2}$ test is applied to the deviation from the expected $1: 1$ ratio. The segregation ratio is the number of affected offspring to total number of offspring, and the penetrance is the ratio of the calculated to theoretical value of the segregation ratio. The segregation ratio for the autosomal dominant families was found to be $p=0.453$, indicating a penetrance of $90.6 \%$. There were in fact 12 pedigrees out of a total of $104(11.5 \%)$ showing reduced penetrance.

$X$-linked families. The method used was that given by Emery ${ }^{49}$ for X-linked recessive inheritance, since no pedigree in the GC series fulfilled the criteria for $\mathrm{X}$-linked dominant transmission. The method used was similar to that used for autosomal dominant inheritance, except that the segregation ratio in this case was the number of affected sons to the total number of sons. There was the added condition that only the male offspring of obligate heterozygotes were considered. This condition would have restricted the number of informative sibships to such a degree that it was decided to consider the whole pedigree in the calculations and not merely the proband's generation.

The segregation ratio for $\mathrm{X}$-linked families was $p=0.47$, which is in good agreement with the theoretical value. The number of informative families was small, as only the sons of obligate heterozygotes were included in the analysis.

IMPLICATIONS FOR GENETIC COUNSELLING

The Genetic Clinic series remains the basis of this study owing to the unique combination of genetic and clinical information it provides. Every single proband, and numerous relatives of probands, were seen by one or 2 of only 3 clinicians, resulting in a remarkable homogeneity in clinical approach. The main conclusions drawn from the results of the various analyses should be considered in the light of corroborative evidence from the Electrodiagnostic series.

Frequency of genetic forms. The frequency of the different genetic forms in the GC series was identified initially by considering the phenotype and the family history. The estimation of the unidentified X-linked proportion in the series has shown that the phenotype is not necessarily distinguishable from the autosomal recessive phenotype in the hemizygote and from the autosomal dominant phenotype in the heterozygote.

In the group of conditions such as retinitis pigmentosa, where there is genetic heterogeneity and the occurrence of phenocopies, it cannot be presumed that all cases which are not demonstrably autosomal dominant or X-linked are necessarily autosomal recessive. Segregation analysis has demonstrated that autosomal recessive transmission may be assumed in a group defined by a number of criteria. It has been shown that autosomal recessive retinitis pigmentosa usually produces early and severe visual loss. Autosomal recessive disease can be assumed if one or more sib is severely affected, particularly if there is parental consanguinity. A proportion of severely affected male simplex and multiplex cases are X-linked, and in these instances the heterozygotes usually show evidence of being mildly affected, in contrast to the heterozygotes for autosomal recessive disease, who at present cannot be distinguished from normal individuals.

If these criteria are applied to the GC series, then the autosomal recessive group comprises: 29 families with evidence of parental consanguinity; 28 multiplex sibships termed 'mixed multiplex'; 8 multiplex sibships termed 'male multiplex'; 109 simplex cases with severe disease. The total number of families in the above group is 174 , which is $40.8 \%$ of the GC series.

The frequency of the different genetic forms in the GC series is therefore as shown in Table 7.

Table 7 Frequency of different genetic forms in the GC series

\begin{tabular}{lcc}
\hline & Identified & Calculated \\
\hline Autosomal dominant & $24.4 \%$ & $24.4 \%$ \\
Autosomal recessive & $6 \cdot 8 \%$ & $40 \cdot 8 \%$ \\
X-linked & $15 \cdot 7 \%$ & $22 \cdot 3 \%$ \\
Mixed multiplex & $6.6 \%$ & - \\
Male multiplex & $4 \cdot 5 \%$ & - \\
Simplex & $41 \cdot 1 \%$ & - \\
Adopted & $0.9 \%$ & $0.9 \%$ \\
Total & $100 \cdot 00$ & $88.4 \%$ \\
\hline
\end{tabular}


The remaining $11.6 \%$ in the calculated total consists of 50 simplex cases with mild disease whose genetic status is uncertain but most of whom are not autosomal recessive.

Genetic counselling. The genetic counselling of autosomal dominant and identifiable $\mathrm{X}$-linked families is straightforward. The counselling of presumably autosomal recessive families depends on a number of factors and differs in multiplex and simplex cases.

(1) Multiplex cases. Autosomal recessive transmission may be justifiably assumed in sibships where females only are affected, or where males and females are equally severely affected. In sibships consisting only of affected males, and in the absence of parental consanguinity, X-linked transmission should always be suspected and every effort made to exclude it by examining obligate or possible heterozygotes.

(2) Simplex cases. The genetic counselling of simplex cases, which account for half the ascertained families, still remains a problem and depends upon various factors such as age, sex, and clinical state. The diagnosis of clinical form is age-dependent and, if the disease is mild, often cannot be made until the patient is in the fourth decade. It can often be made in the second decade when the disease is severe. This can be an important factor in a situation where parents of one affected child are concerned about the risk to further children. It is usually possible to diagnose severe disease when the proband is of childbearing age and wishes to know the risk of transmitting the disease.

Males without parental consanguinity and with severe or moderately severe disease form $74 \%$ $(76 / 103)$ of the total, and, of these, $21 \%(36 / 76)$ are estimated to be $\mathrm{X}$-linked, the remainder being autosomal recessive $(79 \%)$. When the disease is severe or moderately severe, the ratio of autosomal recessive to $X$-linked is 4 to 1 . The risk of transmitting autosomal recessive disease is very small, as it depends upon the frequency of heterozygotes in the general population. In $\mathrm{X}$-linked disease sons are unaffected but all daughters are obligate heterozygotes. Males with severe or moderately severe disease, whose genetic status is uncertain, have negliglible chance of producing affected children (provided they have not married a relative), but have a 1:10 chance of producing a daughter who is a heterozygote for $\mathrm{X}$-linked disease.

Males with mild disease form the remaining $26 \%$ of the total, and the problem of their genetic status is not entirely resolved. They may represent fresh autosomal dominant mutations, autosomal dominant transmission with reduced penetrance, or unidentified phenocopies. Taking into account the $\mathbf{9 0 . 6 \%}$ penetrance in autosomal dominant retinitis pigmentosa and the small incidence of phenocopies, this group of males with mild disease have approximately a $45 \%$ chance of producing affected children who will also have the mild form of the disease.

Similarly, females without parental consanguinity and with severe or moderately severe disease comprise $68 \%(49 / 72)$ of the total and may be counselled on the basis that they have autosomal recessive disease. The remaining $32 \%$ of the total are females with mild disease, a number of whom may be expected to be obligate heterozygotes for $\mathrm{X}$-linked disease and the others fresh autosomal dominant mutations, autosomal dominant transmission with reduced penetrance, or unidentified phenocopies. In contrast to males in whom X-linked transmission is suspected but cannot be confirmed due to the lack of availability of obligate heterozygotes, a precise diagnosis can usually be established in the females by the time they are of childbearing age. It is usually possible to distinguish clinically between females who are obligate heterozygotes for $\mathrm{X}$-linked disease and those who have autosomal dominant disease. The former have a $50 \%$ chance of their sons having severe disease, while the latter have a $45 \%$ chance of their children having mild disease.

Comment. The methods of analysis which were used are those currently available, and they are based on some assumptions and conditions which are not always realised in clinical practice. The systematic recording of ascertainments, referrals, and similar data is a prerequisite of a certain type of statistical analysis. It is an approach which is admirably suited to the computerised methods of the present day, but which must serve and not dominate the clinician in the practice of medicine.

It is perhaps apt to end with the observation that after 20 years of collecting families with retinitis pigmentosa Nettleship ${ }^{2}$ found that half his cases had no family history and no parental consanguinity. The findings in this study are remarkably similar, but it is hoped that the conclusions which are tentatively submitted will be of some assistance to the clinician in giving genetic advice and to those who continue the research into this disease.

\section{Conclusions}

(1) The various phenotypes in retinitis pigmentosa cannot always be easily recognised in the absence of a corroborative family history.

(2) The X-linked form of retinitis pigmentosa is a common form of the disease in England and Wales. It was identified clinically as $15.7 \%$ and calculated as $22.3 \%$ in the Genetic Clinic series, and it was estimated that a minimum of $15 \%$ of families in the 
combined Genetic Clinic and Electrodiagnostic series had X-linked disease.

(3) Simplex cases without parental consanguinity constitute $41.1 \%$ of families in the Genetic Clinic series and approximately $50 \%$ of the combined Genetic Clinic and Electrodiagnostic Clinic series. The results of segregation analysis and clinical heterogeneity indicate that no more than $70 \%$ of all simplex cases in the GC series are autosomal recessive.

(4) The criteria for autosomal recessive transmission in retinitis pigmentosa should include severe disease.

(5) The clinical assessment of simplex cases is essential for determining their genetic status. There were 192 simplex cases with or without parental consanguinity in the GC series, and, of these, $50(26 \%)$ were mildly affected with disease resembling autosomal dominant disease in clinical form and progression. It is considered that this is not wholly accounted for by a mild phenotype in autosomal recessive disease, but more probably evidence of fresh autosomal dominant mutations, autosomal dominant transmission with reduced penetrance, the heterozygous state of $\mathrm{X}$-linked disease in some of the females, and phenocopies.

(6) The results in the 2 series reflect a bias of ascertainment inherent in each.

(7) The excess of female probands in the autosomal dominant families in the Genetic Clinic series may indicate a greater concern for the genetic implications of the disease in women than in men.

I thank Mr Barrie Jay and Professor Alan Bird for allowing me access to the notes of the Genetic Clinic and for their clinical assessment of cases in this study. I am grateful to Professor G. B. Arden and Mr J. H. Kelsey for allowing me access to the notes of the Electrodiagnostic Department at Moorfields Eye Hospital. I am also grateful to Mrs Vanessa Hanna for secretarial help.

This research was supported in part by MRC grant No G80/0986/7/N and by a grant from the National Retinitis Pigmentosa Foundation, Inc.

\section{References}

1 Hutchinson $\mathrm{J}$. On retinitis pigmentosa and allied affections, as illustrating the laws of heredity. Ophthalmic Rev 1882; 1: 2-7.

2 Nettleship E. On some hereditary diseases of the eye. Trans Ophthalmol Soc UK 1909; 29: 57-198.

3 Bell J. Retinitis pigmentosa and allied diseases. In: Pearson K, ed. Treasury of Human Inheritance. Cambridge: Cambridge University Press, 1922: 2 (1).

4 Ammann F, Klein D, Böhringer HR. Résultats préliminaires sur la fréquence et la distribution géographique des dégénérescences tapéto-rétiniennes en Suisse (étude de cinq cantons). J Genet Hum 1961; 10: 99-127.

5 Ammann F, Klein D, Franceschetti A. Genetic and epidemiological investigations on pigmentary degeneration of the retina and allied disorders in Switzerland. J Neurol Sci 1965; 2: 183-96.

6 Biro I. Ueber den Zusammenhang von Degeneratio pigmentosa retinae und Storungen des Gehörs. Ophthalmologica 1944; 107: $149-57$.
7 François J. Dégénérescence pigmentaire de la rétine à hérédité dominante. Bull Soc Belge Ophtalmol 1935; 70: 79-86.

8 François J. Chorioretinal heredodegeneration. Proc $R$ Soc Med 1961;54: 1109-18.

9 Jay B. Hereditary aspects of pigmentary retinopathy. Trans Ophthalmol Soc UK 1972; 92: 173-8.

10 Wibaut F. Studien uber Retinitis pigmentosa. Klin Monatsbl Augenheilkd 1931; 87: 298-307.

11 Botermans CHG. Primary pigmentary retinal degeneration and its association with neurological diseases. In: Vinken PJ, Bruyn GW, eds. Handbook of Clinical Neurology: Neuroretinal degenerations. New York: American Elsevier, 1972; 13: 148-378.

12 Deutman AF. Rod-cone dystrophy: Primary, hereditary, pigmentary retinopathy, retinitis pigmentosa. In: Krill AE. Hereditary Retinal and Choroidal Diseases. Hagerstown: Harper and Row, 1977; 2: 479-576.

13 Duke-Elder S, Dobree JH. System of Ophthalmology. Diseases of the Retina. London: Henry Kimpton, 1967; 10: 577-628.

14 Franceschetti A, François J, Babel J. Les hérédo-dégénérescences chorio-rétiniennes. Paris: Masson, 1963; 1: 203-369.

15 François J. Heredity in Ophthalmology. St Louis: Mosby, 1961: 441-53.

16 François J. Counseling in hereditary eye disorders. In: Bellow JG, ed. Contemporary Ophthalmology. Baltimore: Williams and Wilkins, 1972: 459-71.

17 Krill AE. Retinitis pigmentosa: a review. Sight Sav Rev 1972; 42: 20-8.

18 Merin S, Auerbach E. Retinitis pigmentosa. Surv Ophthalmol 1976; 20: 303-46.

19 Scheie HG, Albert DM. Adler's Textbook of Ophthalmology. Philadelphia: Saunders, 1969: 130-3.

20 Sorsby A. Ophthalmic Genetics. London: Butterworths, 1970: 134

21 Hussels I. Une famille atteinte de rétinopathie pigmentaire liée au sexe, de maladie de Parkinson et d'autres troubles neuropsychiatriques. J Genet Hum 1967; 16: 106-55.

22 Diem M. Retinitis punctata albescens et pigmentosa. Klin Monatsbl Augenheilkd 1914; 53: 371-9.

23 Falls HF, Cotterman C. Choroidal degeneration. A sex-linked form in which heterozygous women exhibit a tapetal-like retinal reflex. Arch Ophthalmol 1948; 40: 683-703.

24 Gasalla ML. L'hérédité dans une famille atteinte de rétinite pigmentaire. Bull Mem Soc Fr Ophtalmol 1931; 44: 169-73.

25 Gonin J. Nouvelles observations de scotome annulaire dans la dégénérescence pigmentaire de la rétine. Ann Oculist (Paris) 1902; 128: 90-107.

26 Hoare GW. Choroido-retinal dystrophy. Br J Ophthalmol 1965 ; 49: 449-59.

27 McKenzie DS. The inheritance of retinitis pigmentosa in one family. Trans Ophthalmol Soc NZ 1951; 5: 79-82.

$28 \mathrm{McQuarrie}$ MD. Two pedigrees of hereditary blindness in man. $J$ Genet 1935; 30: 147-53.

29 Ricci A, Ammann F, Franceschetti A. Reflet tapetoide reversible (phénomène de Mizuo inverse) chex des conductrices de rétinopathie pigmentaire récessive liée au sexe. Bull Mem Soc Fr Ophtalmol 1963; 76: 31-5.

30 Tanabe U. Genetic study of retinal pigmentary dystrophy (retinitis pigmentosa) in Japan. Jinrui Idengaku Zasshi 1972; 16: $119-54$

31 Bird AC. X-linked retinitis pigmentosa. Br J Ophthalmol 1975; 59: $177-99$.

32 François J. Chorioretinal degeneration or retinitis pigmentosa of intermediate sex-linked heredity. Doc Ophthalmol 1962; 16: $111-27$.

33 Faber J. Retinitis pigmentosa in Israel. Statistical-clinical survey. MD Thesis, Jerusalem: Hebrew University, Vision Research Laboratory, 1970.

34 Imaizumi K. Retinitis pigmentosa: genetic carriers and early cases. S Afr Arch Ophthalmol 1974; 2: 257-69. 
35 Motohashi A. The prevalence of pigment degeneration of the retina. Jpn J Clin Ophthalmol 1968; 22: 27-35.

36 Panteleeva OA. On the hereditary tapeto-retinal degenerations. Vestn Oftalmol 1969; 1: 53-6.

37 Jay B. Recent advances in ophthalmic genetics: genetic counselling. Br J Ophthalmol 1974; 58: 427-37.

38 Jay B. Retinitis pigmentosa in childhood-diagnosis, counseling and prevention. Metab Ophthalmol 1978; 2: 221-2.

39 Boughman JA. Population genetic studies of retinitis pigmentosa. PhD Thesis, Indiana University, 1978.

40 Fishman GA. Retinitis pigmentosa. Genetic percentages. Arch Ophthalmol 1978; 96: 822-6.

41 Pearlman JT, Flood TP, Seiff SR. Retinitis pigmentosa without pigment. Am J Ophthalmol 1976; 81: 417-9.

42 Bell J. A determination of the consanguinity rate in the general hospital population of England and Wales. Ann Eugen 1940; 10: 370-91.

43 Jay B, Bird A, Jay M. The incidence of the different genetic forms of retinitis pigmentosa. Doc Ophthalmol Proc Series 1978; 17: 313-8.

44 François J, Verriest G. Etude biométrique de la rétinopathie pigmentaire. Ann Oculist (Paris) 1962; 195: 937-51.

45 Fraser GR. Sex-linked recessive congenital deafness and excess of males in profound childhood deafness. Ann Hum Genet 1965; 29: $171-96$.

46 Nettleship E. On retinitis pigmentosa and allied diseases. $R$ Lond Ophthal Hosp Rep 1907-8; 17: 1-56, 151-66, 333-426.
47 Imaizumi K. Statistical investigation on retinitis pigmentosa. Jpn J Clin Ophthalmol 1971; 25: 293-304.

48 Moorfields Eye Hospital Biennial Report April 1977 to March $1979 ; 41$.

49 Emery AEH. Methodology in Medical Genetics. An Introduction to Statistical Methods. Edinburgh, London, and New York: Churchill Livingstone, 1976; 34-50.

$50 \mathrm{Li} \mathrm{CC}$. Human Genetics, Principles and Methods. New York: McGraw-Hill, 1961: 58-78.

51 Mayo O. Fundamental and population genetics. In: Fraser G, Mayo, eds. Textboak of Human Genetics. Oxford: Blackwell, 1975: 47.

52 Crow JF. Problems of ascertainment in the analysis of family data. In: Neel JV, Shaw, M, Schull W, eds. Genetics and the Epidemiology of Chronic Diseases. Department of Health, Education and Welfare, Publication 1163, 1965: 23-44.

53 Bailey NTJ. The estimation of the frequencies of recessives with incomplete multiple selection. Ann Eugen 1951; 16: 215-22.

54 Haldane JBS. The estimation of the frequencies of recessive conditions in man. Ann Eugen 1938; 8: 255-62.

55 Morton NE. Genetic tests under incomplete ascertainment. Am J Hum Genet 1959; 11: 1-16.

56 Morton NE, Chung CS. Formal genetics of muscular dystrophy. Am J Hum Genet 1959; 11: 360-79. 